Received 11/06/2018 Review began 11/08/2018 Review ended 11/21/2018 Published 11/26/2018 Corrected 02/04/2019

(c) Copyright 2018

Sinha et al. This is an open access article distributed under the terms of the Creative Commons Attribution License CC-BY 3.0., which permits unrestricted use, distribution, and reproduction in any medium, provided the original author and source are credited.

\section{Corrected: Type II Renal Tubular Acidosis Secondary to Topiramate: A Review}

Ankur Sinha ${ }^{1}$, Phone Oo ${ }^{2}$, Muhammad U. Asghar ${ }^{3}$, Hira A. Cheema ${ }^{4}$, Sanwal S. Mehta ${ }^{5}$, Joshua C. Leinwand ${ }^{3}$, Kalyana Janga ${ }^{6}$

1. Pulmonary and Critical Care, Maimonides Medical Center, Brooklyn, USA 2. Department of Nephrology, Vassar Brothers Medical Center, poughkeepsie, USA 3. Surgery, New York University Langone Medical Center, New York, USA 4. Internal Medicine, Markham Stouffville Hospital, Markham, CAN 5. Internal Medicine, Maimonides Medical Center, Brooklyn, USA 6. Department of Nephrology, Maimonides Medical Center, New York, USA

Corresponding author: Ankur Sinha, ansinha@maimonidesmed.org

\section{This article has been corrected.}

Correction date: February 04, 2019. Cite this correction as Sinha A, Oo P, Asghar M U, et al. (February 04, 2019) Correction: Type II Renal Tubular Acidosis Secondary to Topiramate: A Review. Cureus 11(2): c17. doi:10.7759/cureus.c17.

Ankur Sinha, Phone Oo and Kalyana Janga were added to the article as authors as they were erroneously excluded from the original submission. It has been confirmed that all three participated in the case and all authors are in agreement regarding their inclusion.

\begin{abstract}
Topiramate (TMP) is a broad-spectrum anticonvulsant drug used to treat a wide variety of seizure disorders, for migraine prophylaxis, and for many other indications. An important side effect of TMP is metabolic acidosis, which is mediated by renal tubular defects. TMP inhibits carbonic anhydrase, an enzyme that is necessary for acid handling in the proximal renal tubule. Patients can present with asymptomatic serum electrolyte derangements, acute change in mental status, hyperventilation, cardiac arrhythmias, or other sequelae of metabolic acidosis and associated respiratory compensation. If taken chronically, TMP can cause renal stone formation, bone mineralization defects, and several other effects secondary to changes in serum and urine $\mathrm{pH}$ and electrolytes. There is no well-studied way to prevent metabolic acidosis in patients taking TMP, but physicians should be vigilant when prescribing this drug to patients with the history of renal diseases and other comorbidities, and aware of this potential etiology of metabolic acidosis. We present a literature review of the underlying mechanisms involved in the development of renal tubular acidosis secondary to TMP and its clinical consequences.
\end{abstract}

Categories: Internal Medicine, Nephrology

Keywords: renal tubular acidosis, topiramate

\section{Introduction And Background}

Topiramate (TMP) is an anticonvulsant drug used to treat epilepsy in adults and children. According to American Academy of Neurology (AAN) guidelines, TMP can be used as initial therapy for newly diagnosed focal and mixed seizure disorders [1]; it is also used as monotherapy for refractory generalized tonic-clonic seizures and focal seizures in adults and children [2]. TMP has also been used for migraine prophylaxis, weight reduction, among other indications [3-5]. TMP is primarily excreted through the kidney and can cause renal tubular acid-base disturbances. With the wide and increasing use of this drug and its potential for renal side effects, it is imperative to consider a patient's comorbidities before prescribing TMP and to be aware of possible drug toxicities when evaluating electrolyte derangements in patients taking this drug.

TMP is approved by the US Food and Drug Administration (FDA) for use in adults and children two years of age or older for epilepsy monotherapy or adjunctive therapy [3]. It is also approved for migraine prophylaxis [4], and for weight reduction in combination with phentermine [5]. Most patients achieve $90 \%$ of the maximum plasma concentration within two hours of oral administration [6]. TMP is unlikely to displace highly protein-bound drugs in the plasma, hence limiting its drug interactions. The predominant route of drug elimination is renal excretion, accounting for about 51\% of TMP elimination [6]. The therapeutic activities and side effects of TMP are mediated by several different mechanisms of action (Figure 1). 


\section{Cureus}

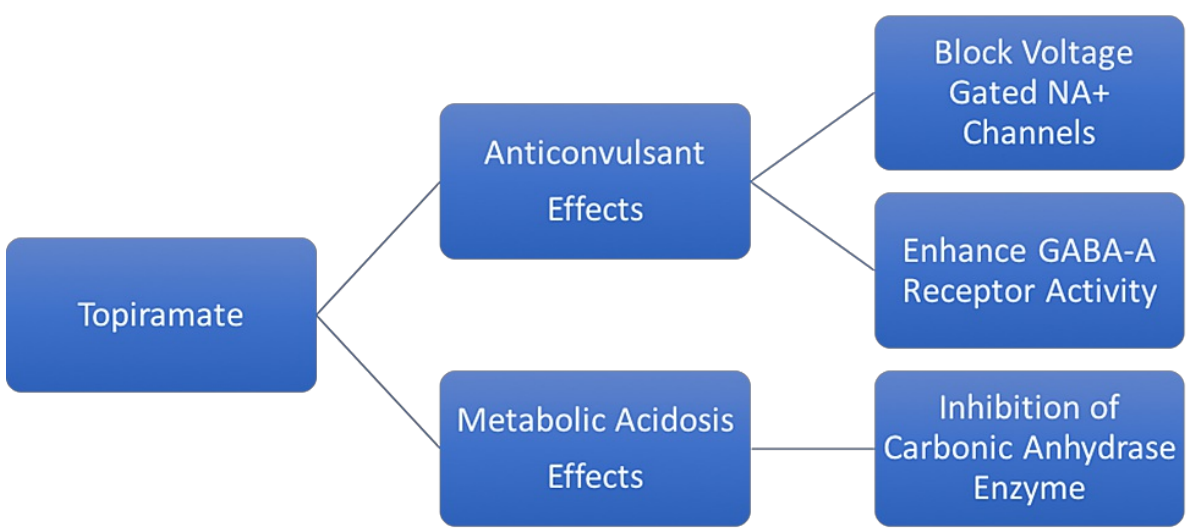

FIGURE 1: Mechanisms of Action of Topiramate.

\section{Review}

Metabolic acidosis occurs when there is an imbalance between the body's production of $\mathrm{H}+$ ions, and the kidneys' ability to excrete $\mathrm{H}+$ ions and resorb $\mathrm{HCO}_{3}$. Metabolic acidosis is classified as either high anion gap (caused by increased production or ingestion of acid and impaired renal acid excretion) or normal anion gap (caused by the loss of bicarbonate from the kidney or gastrointestinal tract).

Renal tubular defects can result in metabolic acidosis due to impaired renal $\mathrm{H}+$ excretion or $\mathrm{HCO}_{3}$ - resorption. Carbonic anhydrase (CA) is an enzyme that catalyzes the formation of $\mathrm{H}^{+}$and $\mathrm{HCO}_{3}$ - from $\mathrm{CO}_{2}$ and $\mathrm{H}_{2} \mathrm{O}$, which is necessary for renal excretion of $\mathrm{H}^{+}$and resorption of $\mathrm{HCO}_{3}$ - in the proximal convoluted tubule (PCT). Of the various types of CA, CA type II (CA-II) predominates in the human kidney, comprising about $95 \%$ of the total CA, while the remaining $5 \%$ consists of CA-IV and CA-XIII [7]. Supuran et al. reported that TMP is a potent inhibitor of CA-II and CA-XIII, and a medium potency inhibitor of CA-IV [8]. Because of its CA-inhibitory activity, especially against CA-II, TMP can impair $\mathrm{H}+$ excretion and $\mathrm{HCO}_{3}$ - absorption in the PCT, leading to increased delivery of $\mathrm{HCO}_{3}$ - in the distal portion of the nephron and induce a normal anion gap metabolic acidosis (Figure 2).

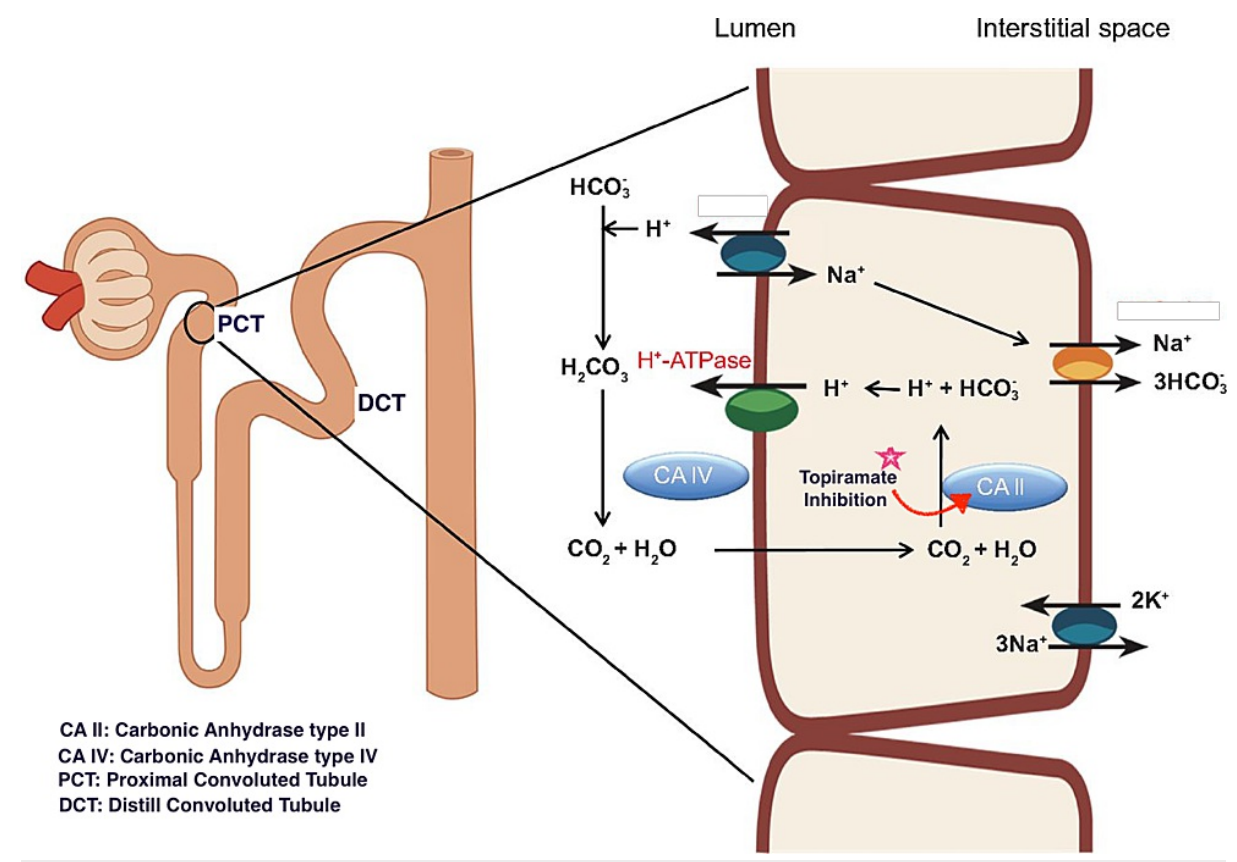

FIGURE 2: Development of Proximal Renal Tubular Acidosis.

Distal (Type 1) renal tubular acidosis (RTA) is characterized by impaired acid secretion from the collecting 


\section{Cureus}

tubules, leading to an inability to secrete acid, and resulting in progressive $\mathrm{H}+$ ion accumulation which manifests clinically as decreased serum $\mathrm{HCO}_{3}-$ [9]. Proximal (Type 2) RTA is caused by an inability to reabsorb $\mathrm{HCO}_{3}$ - from the PCT. Since the PCT reabsorbs 85 to $90 \%$ of the filtered load of $\mathrm{HCO}_{3}{ }^{-}$, inhibition of CA-II by TMP can lead to Type 2 RTA. Type 2 RTA can also result from Fanconi syndrome, a generalized resorption defect affecting $\mathrm{HCO}_{3^{-}}$, glucose, phosphate, amino acids, and tubular proteins. The differences between proximal and distal RTA are shown in Table 1.

\begin{tabular}{|c|c|c|c|}
\hline & Distal (Type 1) RTA & Proximal (Type 2) RTA & Study Ref. \\
\hline Pathophysiology & Failure to secrete $\mathrm{H}^{+}$and reabsorb $\mathrm{K}^{+}$Ions & Failure to reabsorb $\mathrm{HCO}_{3}$ & \\
\hline Location & Collecting \& distal tubules & Proximal Tubules & \\
\hline Urine $\mathrm{pH}$ & $>6.0$ & $<5.5$ & 13 \\
\hline Urine $\mathrm{HCO}_{3}^{-}$ & Normal & Increased & 13 \\
\hline Fractional Excretion of $\mathrm{HCO}_{3}^{-}$ & $<5 \%$ & $>15 \%$ & 13 \\
\hline Serum Potassium & Hypokalemia & Hypokalemia & \\
\hline
\end{tabular}

TABLE 1: Type 1 and Type 2 Renal Tubular Acidosis (RTA).

There are several reports in the literature of an association between TMP and hyperchloremic normal anion gap metabolic acidosis with an alkaline urine and positive urine anion gap (due to increased urine $\mathrm{HCO}_{3}$ )

$[10,11]$. In many cases, patients may be asymptomatic. Burmeister et al. [12] reported a case of severe metabolic acidosis in a 46-year-old woman who was prescribed TMP, $100 \mathrm{mg}$ per day for three months; Ozer and Altunkaya described a similar presentation in a 58-year-old man [11]. Other studies have demonstrated the role of TMP in lowering plasma $\mathrm{HCO}_{3^{-}}$; in a cross-sectional study, Welch et al. compared 32 TMP-treated subjects and 50 healthy volunteers and concluded that TMP-treated subjects had significantly lower serum total carbon dioxide content [13]. In another study, there was a $2.0 \mathrm{~kg}$ mean decline in weight after three months' use of TMP [14].

Metabolic acidosis can present with complications due to respiratory compensation, notably hyperventilation, fatigue, altered mental status; more severe cases can lead to cardiac arrhythmia and coma. Stowe et al. [15] described a case of TMP-induced metabolic acidosis in a 20-year-old man presenting with disorientation, somnolence, agitation, and headache for two weeks.

Renal tubular acidosis caused by TMP can lead to decreased urine citrate concentration; hypocitraturia combined with decreased urine acidification in the distal convoluted tubules can contribute to the formation of calcium phosphate stones [16, 17]. The risk of the renal stone formation increases to 10 folds with the use of TMP. Warner et al. [18] in a study involving four subjects, reported that urinary citrate levels decreased significantly and rapidly after the start of TMP therapy and continued to decrease with escalating doses. Other common sides in adults are related to central nervous system (CNS) including paresthesia, fatigue, dizziness, somnolence, and mood symptoms [19]. TMP is also associated with oligohydrosis due to its inhibition of carbonic anhydrase within the sweat glands leading to impaired seat rate which is associated with heat intolerance and hyperthermia particularly in children [20].

There are no evidence-based or universally accepted management strategies to treat RTA secondary to TMP. TMP discontinuation should be considered in patients with persistent severe RTA. In some reports, normalization of mental status in patients with TMP-induced metabolic acidosis took 48 hours after the discontinuation of TMP [17]. Treatment with an alkali such as sodium bicarbonate or potassium citrate and citric acid can be used to restore normal serum $\mathrm{HCO}_{3}$ - in patients with RTA. This can also decrease urinary calcium excretion and increase urinary citrate excretion which can prevent renal stone formation and improve bone disease in adults [21]. Adequate hydration whilst using TMP should be encouraged as it can reduce the risk of developing renal stones.

\section{Conclusions}

Topiramate has been demonstrated to be a potent inhibitor of some carbonic anhydrase isoenzymes, which can result in the development of type 2 renal tubular acidosis, normal anion gap metabolic acidosis, and nephrolithiasis as side effects from its use. Clinicians must remain vigilant to the clinical manifestations of metabolic acidosis, and aware of this possible etiology. 


\section{Additional Information \\ Disclosures}

Conflicts of interest: In compliance with the ICMJE uniform disclosure form, all authors declare the following: Payment/services info: All authors have declared that no financial support was received from any organization for the submitted work. Financial relationships: All authors have declared that they have no financial relationships at present or within the previous three years with any organizations that might have an interest in the submitted work. Other relationships: All authors have declared that there are no other relationships or activities that could appear to have influenced the submitted work.

\section{References}

1. French JA, Kanner AM, Bautista J, et al.: Efficacy and tolerability of the new antiepileptic drugs II: treatment of refractory epilepsy. Report of the Therapeutics and Technology Assessment Subcommittee and Quality Standards Subcommittee of the American Academy of Neurology and the American Epilepsy Society. Neurology. 2004, 62:1261-1273. 10.1212/01.WNL.0000123695.22623.32

2. Ben-Menachem E: Clinical efficacy of topiramate as add-on therapy in refractory partial epilepsy: the European experience. Epilepsia. 1997, 38:S28-S30. 10.1111/j.1528-1157.1997.tb04514.x

3. Food and Drug Administration (FDA). FDA labelling information . (2018). Accessed: November 24, 2018: http://www.accessdata.fda.gov/scripts/cder/drugsatfda/index.cfm.

4. Ramadan NM, Buchanan TM: New and future migraine therapy. Pharmacol Ther. 2006, 112:199-212. 10.1016/j.pharmthera.2005.04.010

5. Supuran CT, Di Fiore A, De Simone G: Carbonic anhydrase inhibitors as emerging drugs for the treatment of obesity. Expert Opin Emerg Drugs. 2008, 13:383-392. 10.1517/14728214.13.2.383

6. Doose DR, Walker SA, Gisclon LG, Nayak RK: Single-dose pharmacokinetics and effect of food on the bioavailability of topiramate, a novel antiepileptic drug. J Clin Pharmacol. 1996, 36:884-891. 10.1002/j.15524604.1996.tb04754.x

7. Purkerson JM, Schwartz GJ: The role of carbonic anhydrases in renal physiology . Kidney Int. 2007, 71:103115. 10.1038/sj.ki.5002020

8. Winum JY, Poulsen SA, Supuran CT: Therapeutic applications of glycosidic carbonic anhydrase inhibitors . Med Res Rev. 2009, 29:419-435. 10.1002/med.20141

9. Laing CM, Unwin RJ: Renal tubular acidosis. J Nephrol. 2006, 19:S46-S52.

10. Izzedine H, Launay-Vacher V, Deray G: Topiramate-induced renal tubular acidosis. Am J Med. 2004, 116:281-282. 10.1016/j.amjmed.2003.08.021

11. Ozer Y, Altunkaya H: Topiramate induced metabolic acidosis. Anaesthesia. 2004, 59:830. 10.1111/j.13652044.2004.03884.x

12. Burmeister JE, Pereira RR, Hartke EM, Kreuz M: Topiramate and severe metabolic acidosis: case report. Arq Neuropsiquiatr. 2005, 63:532-534.

13. Welch BJ, Graybeal D, Moe OW, Maalouf NM, Sakhaee K: Biochemical and stone-risk profiles with topiramate treatment. Am J Kidney Dis. 2006, 48:555-563. 10.1053/j.ajkd.2006.07.003

14. Majkowski J, Neto W, Wapenaar R, Van Oene J: Time course of adverse events in patients with localizationrelated epilepsy receiving topiramate added to carbamazepine. Epilepsia. 2005, 46:648-653. 10.1111/j.15281167.2005.35904.x

15. Stowe CD, Bollinger T, James LP, Haley TM, Griebel ML, Farrar HC 3rd: Acute mental status changes and hyperchloremic metabolic acidosis with long-term topiramate therapy. Pharmacotherapy. 2000, 20:105-109. 10.1592/phco.20.1.105.34662

16. Kuo RL, Moran ME, Kim DH, Abrahams HM, White MD, Lingeman JE: Topiramate-induced nephrolithiasis. J Endourol. 2002, 16:229-231. 10.1089/089277902753752188

17. Tawil R, Moxley RT 3rd, Griggs RC: Acetazolamide-induced nephrolithiasis: implications for treatment of neuromuscular disorders. Neurology. 1993, 43:1105-1106. 10.1212/WNL.43.6.1105

18. Warner BW, LaGrange CA, Tucker T, Bensalem-Owen M, Pais VM Jr: Induction of progressive profound hypocitraturia with increasing doses of topiramate. Urology. 2008, 72:29-32. 10.1016/j.urology.2008.01.042

19. Sankar R, Ramsay E, McKay A, Hulihan J, Wiegand F: A multicenter, outpatient, open-label study to evaluate the dosing, effectiveness, and safety of topiramate as monotherapy in the treatment of epilepsy in clinical practice. Epilepsy Behav. 2009, 15:506-512. 10.1016/j.yebeh.2009.06.021

20. de Carolis P, Magnifico F, Pierangeli G, Rinaldi R, Galeotti M, Cevoli S, Cortelli P: Transient hypohidrosis induced by topiramate. Epilepsia. 2003, 44:974-976. 10.1046/j.1528-1157.2003.40702.x

21. Brenner RJ, Spring DB, Sebastian A, McSherry EM, Genant HK, Palubinskas AJ, Morris RC Jr: Incidence of radiographically evident bone disease, nephrocalcinosis, and nephrolithiasis in various types of renal tubular acidosis. N Engl J Med. 1982, 307:217-221. 10.1056/NEJM198207223070403 